\title{
Does Robot-assisted Surgery in Urology Has Benefits? The Current Status
}

\author{
(1) Cem Şah MD¹, ๑ Barış Kuzgunbay MD² \\ ${ }^{1}$ Medline Hospital, Clinic of Urology, Adana, Turkey \\ 2 Başkent University, Department of Urology, Adana, Turkey
}

\begin{abstract}
Minimally invasive surgery has gradually replaced the conventional surgery with the introduction of laparoscopy. Subsequently, with intensive advertisement and marketing strategies, robot-assisted surgery became popular and robot-assisted surgery has been used in almost every surgical procedure. Despite its high cost, the robotic platform, which has proven its general advantages such as less hospital stay and less blood loss, has become controversial in the literature in terms of cost effectiveness. In this study, the advantages and disadvantages of the robot-assisted surgery in urology have been reviewed in the light of current literature.
\end{abstract}

Keywords: Robotic surgery, cost-benefit, urology

\section{Introduction}

The word robot was first used by Karel Capek in 1921 in Rossum's Universal Robots (1). The term is derived from the word "Robota", which means forced labor in the Czech language. In Capek's play, robots used to help people in all their jobs, but then the robots took the place of their owners and tried to dominate the world (2).

EndoAssist, probably the first surgical robot, was used in 1990 (2). The first robot-assisted hip replacement was performed in 1992 with Robodoc in California (3). AESOP 1000, the first commercial robot, was used in laparoscopic surgery in 1993 to hold the endoscopic camera. It has been shown that the robot uses the camera more efficiently with less shaking than the human (4). The Zeus robotic surgical system was first used transatlantically in 2001 by a surgeon in New York during a cholecystectomy procedure in France (5).

In the 2000s, with the development of the Da Vinci surgical system, there was a huge leap in the use of robots in surgery. The basic principle of the robot system, which is based on the surgeon's handling of three or four robotic arms in the console, has three main components: Surgeon console, patient-side cart and vision system. Although the first literature studies on robotic surgery have been reported in the field of cardiac surgery, most of the operations have been performed in the field of urology recently (2).

Robot has been used in the field of urology in many operations such as adrenalectomy, simple and radical nephrectomy, partial nephrectomy, vena cava thrombectomy, nephroureterectomy, live donor nephrectomy, renal transplantation, pyeloplasty, ureter surgery, radical and partial cystectomy, bladder augmentation, simple and radical prostatectomy, retroperitoneal lymph node dissection, varicocelectomy, testicular sperm extraction, re-anastomosis after vasectomy and spermatic cord denervation (6). Aside from this wide range of applications, robot has been questioned in terms of cost effectiveness even in areas such as radical prostatectomy, radical and partial nephrectomy, where it is used most.

The first robot-assisted radical prostatectomy was quickly accepted by urologists after its description in 2000 and it has become the most widely used field of robotic surgery today $(6,7)$. In a systematic review, robot-assisted radical prostatectomy, laparoscopic prostatectomy and conventional surgery were compared, and there was no difference in terms of complications, oncologic outcomes, erectile dysfunction and urinary incontinence, but the laparoscopic and robot-assisted groups were similar in terms of blood transfusion rates and short duration of hospital stay, however, robot-assisted group was found to be more advantageous than the surgical group (8). In a study of 2625 patients comparing robot-assisted and conventional prostatectomy, no statistically significant difference was found in terms of urinary incontinence and surgical margins; however, a statistically significant difference was observed in favor of the robot in terms of erectile dysfunction (9). Canada Ontario Health Technology Advisory Committee compared robot-assisted radical prostatectomy with conventional radical prostatectomy in terms of cost and benefit. In conclusion, they stated that there was no high-quality evidence that robotassisted prostatectomy had a benefit to explain the additional cost of $\$ 6000$ per patient for cure rate, urinary incontinence and erectile dysfunction compared to conventional surgery (10). 
Another area where robotic surgery is widely used in urology is radical nephrectomy. In a meta-analysis of 23,753 patients by Jeong et al. (11), 18,573 patients underwent laparoscopic radical nephrectomy and 5,180 patients underwent robotic radical nephrectomy between 2003 and 2015. In the study, it was reported that both methods were similar in terms of the incidence of major complications, blood transfusion rate, length of hospital stay, but robotic surgery was disadvantageous in terms of operative time and hospital cost. The use of the robot in radical nephrectomy does not provide the advantage of easier resection as in partial nephrectomy. Since there is no need for more comfortable intracorporeal suturing such as in radical prostatectomy and pyeloplasty, no superiority to conventional laparoscopy has been demonstrated. However, it has been reported that the number of robotic radical nephrectomies has increased considerably in recent years compared to laparoscopic surgery. In the guidelines, there are increasing studies reporting that robotic surgery makes a difference in the treatment of $\mathrm{T} 3$ tumors, although laparoscopic radical nephrectomy is routinely recommended in T1 renal tumors (11-16).

Robotic partial nephrectomy is also one of the popular uses of robotics. In a meta-analysis by Shen et al. (17), conventional partial nephrectomy was compared with robotic partial nephrectomy in 3024 patients. As a result, the advantages of robot-assisted partial nephrectomy such as less hospital stay, less perioperative complications and less blood loss were demonstrated, however, operative time and warm ischemia time were longer. There were no differences in criteria such as transfusion rates, positive surgical margins, and postoperative glomerular filtration rate changes. In a meta-analysis comparing robotic and laparoscopic partial nephrectomy in T1a tumors, two methods were found equivalent (18). In a series of 216 patients published by Wang et al. (19), patients with a RENAL nephrometry score of 7 or more were evaluated and the perioperative, functional, and oncologic results were found to be similar.

In 2003, after the first robot-assisted radical cystectomy was described by Menon et al. (20), the use of the robot in this field increased rapidly over the years. In a nonsystematic analysis, robot-assisted radical cystectomy was found to be superior to conventional radical cystectomy in terms of estimated blood loss, transfusion rate, gastrointestinal recovery, narcotic analgesic requirement, and hospital stay. The cost, operative time, and metastasis to extra-pelvic lymph nodes and peritoneum were more likely to occur in patients undergoing robot-assisted surgery. There was no difference in terms of urinary incontinence, postoperative quality of life, positive surgical margin, number of removed lymph nodes, and recurrence (21). An analysis from randomized controlled studies indicated that robot-assisted cystectomy did not reduce postoperative complication rate and length of hospital stay, and postoperative quality of life was similar to conventional radical cystectomy (22).

In a meta-analysis of 1162 patients by Economopoulos et al. (23) evaluating laparoscopic and robot-assisted adrenalectomy, there was no difference in terms of intraoperative and postoperative complications, mortality, shift to laparotomy and hemorrhage. Operative time in the robotic arm was longer but the hospital stay was shorter. In a systematic analysis performed by Tang et al. (24), robot-assisted adrenalectomy was reported to be a safe alternative with the advantage of less hemorrhage and less hospital stay compared to laparoscopy.

In recent years, robotic surgery has been used in pediatric patients, especially in pyeloplasty operations. In a study conducted in public and training hospitals in the USA, a total of 12,662 pediatric pyeloplasty operations, including conventional, laparoscopic and robotic, were compared, and similar complication rates were reported in all three methods. The cost of robotic surgery was significantly higher than conventional and laparoscopic surgery. The operative time of robotic and laparoscopic pyeloplasty was longer than that of conventional pyeloplasty, but the mean length of hospital stay was same for all methods. Although it did not reach statistical significance, the mean length of hospital stay in robotic surgery was reported to be 17 hours less than conventional surgery. It was commented that this period did not have a significant financial advantage, but that it might have prevented possible loss of work wages by assuming that parents stayed with the children. The study suggested laparoscopic pyeloplasty as the most suitable method among these three methods because of being minimally invasive, having perioperative results similar to conventional pyeloplasty, and similar or lower cost (25).

Today, with the advertising and marketing strategy of the robot, the perception that surgeons who do not perform robotic surgery is a $2^{\text {nd }}$ class surgeon and that every operation can be performed with the robot has been created (26). The popularity of robotic surgery has also affected physicians. In a recent survey of 238 urology physicians, a large number of physicians reported that robot-assisted surgery was not the gold standard for prostatectomy, cystectomy, and nephrectomy, but that they could recommend this method for themselves or their families if necessary (27). Similarly, robot-assisted surgery has altered the patient's perception of operation. In a study, it was found that patients with robot-assisted radical prostatectomy surgery were emotionally more peaceful and comfortable than those who underwent conventional surgery, and those who had open surgery were more anxious (28).

One of the most important advantages proved in favor of robotic surgery in the above- mentioned studies is the shorter hospital stay. However, in countries like ours with low minimum wages and cheap labor, the economic disadvantage of short hospital stay is very insignificant compared with the high cost of the robot. On the other hand, even in developing countries, which lack access to effective health services and where even a clean water supply and sewerage network are not sufficient, robots have been purchased. Ten Da Vinci robotic systems were installed in public hospitals in South America, including four in Brazil, three in Mexico, two in Argentina and one in Venezuela. In a study evaluating the results of these clinics, it was concluded that half of these programs were stopped temporarily or permanently due to the cost of disposable instruments, and that these programs could not be sustained with the financing of social security institutions and the robotic surgery program was likened to a sand castle (26). Cost is also an important burden for hospitals. Some studies have shown that performing more operations reduces the cost of the robotic 
system. In other words, using the robotic system more makes the system more profitable for the hospital. In a study, it was calculated that it is necessary to make an average of 150-250 robotic cases per year in order to obtain a Da Vinci system and meet its sustainable cost within 6 years (29).

\section{Conclusion}

Other important advantages of robotic surgery over conventional surgery are less bleeding and better cosmetic appearance. However, laparoscopic surgery provides similar results with less cost, less bleeding, short hospital-stay and cosmetic advantage. For this reason, widespread use of laparoscopic surgery, which can be applied in almost every hospital condition in our country, will be a very appropriate health policy both in terms of access to quality health care of the society and national economy. For this purpose, both residents and urologists should be prepared with periodic courses and practical trainings to be equipped to perform this surgery.

\section{Ethics}

Peer-review: Externally peer-reviewed.

\section{Authorship Contributions}

Surgical and Medical Practices: C.Ş., Concept: C.Ş., B.K., Design: C.Ş., Data Collection or Processing: C.Ş., B.K., Analysis or Interpretation: C.Ş., B.K., Literature Search: C.Ş., B.K., Writing: C.S.

Conflict of Interest: No conflict of interest was declared by the authors.

Financial Disclosure: The authors declared that this study received no financial support.

\section{References}

1. Shah J, Mackay S, Rockall T, et al. "Urobotics": Robots in urology. BJU Int 2001;88: 313-320.

2. Murphy D, Challacombe B, Khan MS, Dasgupta P. Robotic technology in urology. Postgrad Med J 2006;82:743-747.

3. Kumar R, Hemal AK. Emerging role of robotics in urology. J Minim Access Surg 2005;1:202-210.

4. Hemal AK, Menon M. Laparoscopy, robot, telesurgery and urology: future perspective. J Postgrad Med 2002;48:39-41.

5. Marescaux J, Leroy J, Gagner M, et al. Transatlantic robot-assisted telesurgery. Nature 2001;413:379-380.

6. Aro T, Mullerad M, Amiel Ge. Expanding the Utilization of Robotic Procedures in Urologic Surgery. Rambam Maimonides Med J 2017:8.

7. Pasticier G, Rietbergen JB, Guillonneau B, et al. Robotically assisted laparoscopic radical prostatectomy: feasibility study in men. Eur Urol 2001;40:70-74

8. Ilic D, Evans SM, Allan CA, et al. Laparoscopic and robot-assisted vs open radical prostatectomy for the treatment of localized prostate cancer: a Cochrane systematic review. BJU Int 2018;121:845-853.

9. Haglind E, Carlsson S, Stranne J, et al. Urinary Incontinence and Erectile Dysfunction After Robotic Versus Open Radical Prostatectomy: A Prospective, Controlled, Nonrandomised Trial. Eur Urol 2015;68:216-225.

10. Robotic surgical system for radical prostatectomy (2017) OHTAC Recommendation,pp.1-4.http://www.hqontario.ca/Portals/0/ Documents/evidence/reports/hta-prostatectomy-1707-en.pdf. Accessed 9 Sep 2017
11. Jeong IG, Khandwala YS, Kim JH, et al. Association of Robotic Assisted vs Laparoscopic Radical Nephrectomy With Perioperative Outcomes and Health Care Costs, 2003 to 2015. JAMA 2017;318:1561-1568.

12. Asimakopoulos AD, Miano R, Annino F, et al. Robotic radical nephrectomy for renal cell carcinoma: a systematic review. BMC Urol 2014;14:75.

13. Yang DY, Monn MF, Bahler CD, Sundaram CP. Does robotic assistance confer an economic benefit during laparoscopic radical nephrectomy? J Urol 2014;192:671-676.

14. Abaza R. Initialseries of robotic radical nephrectomy with vena caval tumor thrombectomy. Eur Urol 2011;59:652-656.

15. Chopra S, Simone G, Metcalfe C, et al. Robot-assisted Level II-III Inferior Vena Cava Tumor Thrombectomy: Step-by-Step Technique and 1-Year Outcomes. Eur Urol 2017;72:267-274.

16. Ljungberg B. (Chair), Albiges L., Bensalah K., et al. Volpe Guidelines Associates: Y. Abu-Ghanem, S. Dabestani, S. Fernández-Pello Montes, F. Hofmann, R. Tahbaz. Renal Cell Carcinoma. EuropeanAsociation of UrologyGuidelines. 2018. https://uroweb.org/guideline/ renal-cell-carcinoma/\#7

17. Shen Z, Xie L, Xie W, et al. The comparison of perioperative outcomes of robot-assisted and open partial nephrectomy: a systematic review and meta-analysis. World J Surg Oncol 2016;14:220.

18. Froghi S, Ahmed K, Khan MS, et al. Evaluation of robotic and laparoscopic partial nephrectomy for small renal tumours (T1a). BJU Int 2013;112:322-333.

19. Wang $Y, M a X$, Huang $Q$, et al. Comparison of robot-assisted and laparoscopic partial nephrectomy for complex renal tumours with a RENAL nephrometry score $\geq 7$ : peri-operative and oncological outcomes. BJU Int 2016;117:126-130.

20. Menon M, Hemal AK, Tewari A, et al. Nerve-sparing robotassisted radical cystoprostatectomy and urinary diversion. BJU Int 2003;92:232-236.

21. Davis RB, Farber NJ, Tabakin AL, et al. Open versus robotic cystectomy: Comparison of outcomes. Investig Clin Urol 2016;57(Suppl 1):36-43.

22. Lauridsen SV, Tønnesen $H$, Jensen BT, et al. Complications and health-related quality of life after robot-assisted versus open radical cystectomy: a systematic review and meta-analysis of four RCTs. Syst Rev 2017;6:150.

23. Economopoulos KP, Mylonas KS, Stamou AA, et al. Laparoscopic versus robotic adrenalectomy: A comprehensive meta-analysis. Int J Surg 2017;38:95-104.

24. Tang K, Li H, Xia D, et al. Robot-assisted versus laparoscopic adrenalectomy: a systematic review and meta-analysis. J Laparoendosc Adv Surg Tech A 2015;25:187-195.

25. Varda BK, Johnson EK, Clark C, et al. National trends of perioperative outcomes and costs for open, laparoscopic and robotic pediatric pyeloplasty. J Urol 2014;191:1090-1095.

26. Secin FP, Coelho R, Monzó Gardiner Jl, et al. Robotic surgery in public hospitals of Latin-America: a castle of sand? World J Urol 2018;36:595-601.

27. Azhar RA, Mobaraki AA, Badr HM, et al. Current status of robotassisted urologic surgery in Saudi Arabia: Trends and opinions from an Internet-based survey. Urol Ann 2018;10:263-269.

28. Ranasinghe $W$, de Silva D, Bandaragoda $T$, et al. Robotic-assisted vs. open radical prostatectomy: A machine learning framework for intelligent analysis of patient-reported outcomes from online cancer support groups. Urol Oncol 2018;36:529.

29. Barbash GI, Glied SA. New technology and healthcare costs--the case of robot-assisted surgery. N Engl J Med 2010;363:701-704. 